\section{Improving biliary-enteric drainage in primary sclerosing cholangitis: experience with endoscopic methods}

\author{
M Lombard, M Farrant, J Karani, D Westaby, R Williams
}

\begin{abstract}
Six jaundiced patients with primary sclerosing cholangitis and a dominant biliary stricture were managed by endoscopic placement of endoprostheses. Five showed considerable improvement within weeks of stenting: their serum bilirubin concentration fell from mean (range) $266 \mu \mathrm{mol} / /$ (63-681) to $65 \mu \mathrm{mol} / 1$ (10280 ) after one month. One patient required a liver transplant at five months because of continued deterioration in hepatic function. Follow up of 12-49 months in the remaining five patients shows sustained biochemical improvement, with repeat cholangiograms indicating doubling of the minimum calibre of the extrahepatic bile duct in four patients and considerable shortening of stricture length in three. Three patients developed sepsis at the time of the initial endoprosthesis insertion: surgical drainage was necessary in one. Endoscopic methods of improving biliaryenteric drainage in jaundiced patients with primary sclerosing cholangitis may be preferable to surgical and percutaneous methods, which may complicate subsequent liver transplantation.
\end{abstract}

Department of

Radiology, King's

College Hospital and

King's College School of

Medicine and Dentistry,

London

M Lombard

M Farrant

J Karani

D Westaby

R Williams

Correspondence to:

Dr D Westaby, The Liver

Unit, King's College Hospital,

Denmark Hill, London

SE5 9RS.

Accepted for publication

31 December 1990
Primary sclerosing cholangitis is a progressive and often fatal disease of the liver, characterised by chronic inflammatory destruction of intrahepatic and extrahepatic bile ducts and associated with recurrent episodes of destructive bacterial cholangitis. ${ }^{12}$ Attempts at influencing the course of this condition using medical therapy have been disappointing,,$^{3-7}$ although preliminary results with ursodeoxycholic acid and methotrexate are promising. ${ }^{89}$ Similarly, attempts at changing the progressive nature of
Clinical details of primary sclerosing cholangitis (PSC) patients at referral

\begin{tabular}{|c|c|c|c|c|c|c|}
\hline & \multicolumn{6}{|c|}{ Patient no } \\
\hline & 1 & 2 & 3 & 4 & 5 & 6 \\
\hline Age (yrs)/sex & $30 \mathrm{~F}$ & $54 M$ & $49 M$ & $25 \mathrm{~F}$ & $40 \mathrm{~F}$ & $31 \mathrm{M}$ \\
\hline Duration of PSC (mths) & 36 & 12 & 1 & 5 & 36 & 96 \\
\hline Duration of jaundice (mths) & 6 & 3 & $\mathrm{i}$ & 5 & 3 & 3 \\
\hline Duration of ulcerative colitis (yrs) & 0.5 & 0 & 21 & 0 & 0 & 0 \\
\hline Bilirubin $(\mu \mathrm{mol} / \mathrm{l})$ & 124 & 63 & 681 & 147 & 476 & 104 \\
\hline Albumin $(\mathrm{g} / \mathrm{l})$ & 36 & 40 & 36 & 34 & 35 & 34 \\
\hline Alkaline phosphatase (iu/l) & 1864 & 631 & 386 & 915 & 1865 & 363 \\
\hline Aspartate transaminase (iu/l) & 215 & 53 & 49 & 65 & 102 & 80 \\
\hline Histology grade & II & IV & I & IV & III & IV \\
\hline
\end{tabular}

the disease by nasobiliary drainage and lavage, with or without instillation of corticosteroids, ${ }^{1011}$ or by surgical resection of dominant hilar strictures, ${ }^{12}$ have not been effective.

Several investigators have shown improvement in clinical, radiological, and biochemical parameters after surgical or percutaneous placement of an endoprosthesis ${ }^{1314}$ or balloon dilatation. ${ }^{1516}$ Some of these procedures have a significant morbidity and others involve extensive surgery, which may not be desirable in the long term in these patients as it may jeopardize the success of future hepatic transplantation..$^{17}$ We describe the clinical course in six severely symptomatic patients with primary sclerosing cholangitis in whom endoprostheses placed endoscopically led to an appreciable and sustained improvement in the clinical, biochemical, and radiological assessment of their disease.

\section{Patients and methods}

Between January 1986 and January 1990, 38 new patients were referred to our unit with confirmed or suspected primary sclerosing cholangitis. The extent of disease was determined by endoscopic retrograde cholangiography (ERC) and liver biopsy. Six patients (16\%) were considered suitable for management by endoprosthesis insertion. This decision was based on the presence of strictures that severely reduced (by $50 \%$ ) the bile duct calibre at the hilum or in the extrahepatic bile ducts, with good intrahepatic filling seen on ERC together with recent onset of deep jaundice (within six months). There were three men and three women, aged 25-54 years. When considered for endoprosthesis insertion, the mean serum bilirubin concentration was $266 \mu \mathrm{mol} / 1$ (range 63-681). Two of the six patients had ulcerative colitis and four had established cirrhosis. All had symptoms of pruritus or fatigue, two had recurrent bacterial cholangitis (at least two episodes in the preceding 12 months), and five of the patients had been referred specifically for consideration of liver transplantation (Table). No patient received specific therapy - for example ursodeoxycholic acid - before or after stenting.

The endoscopic procedures were carried out with antibiotic prophylaxis; intravenous amoxycillin $(500 \mathrm{mg})$ and either ceftazidine $(2 \mathrm{~g})$ or gentamicin $(80 \mathrm{mg}$ ) were given immediately 

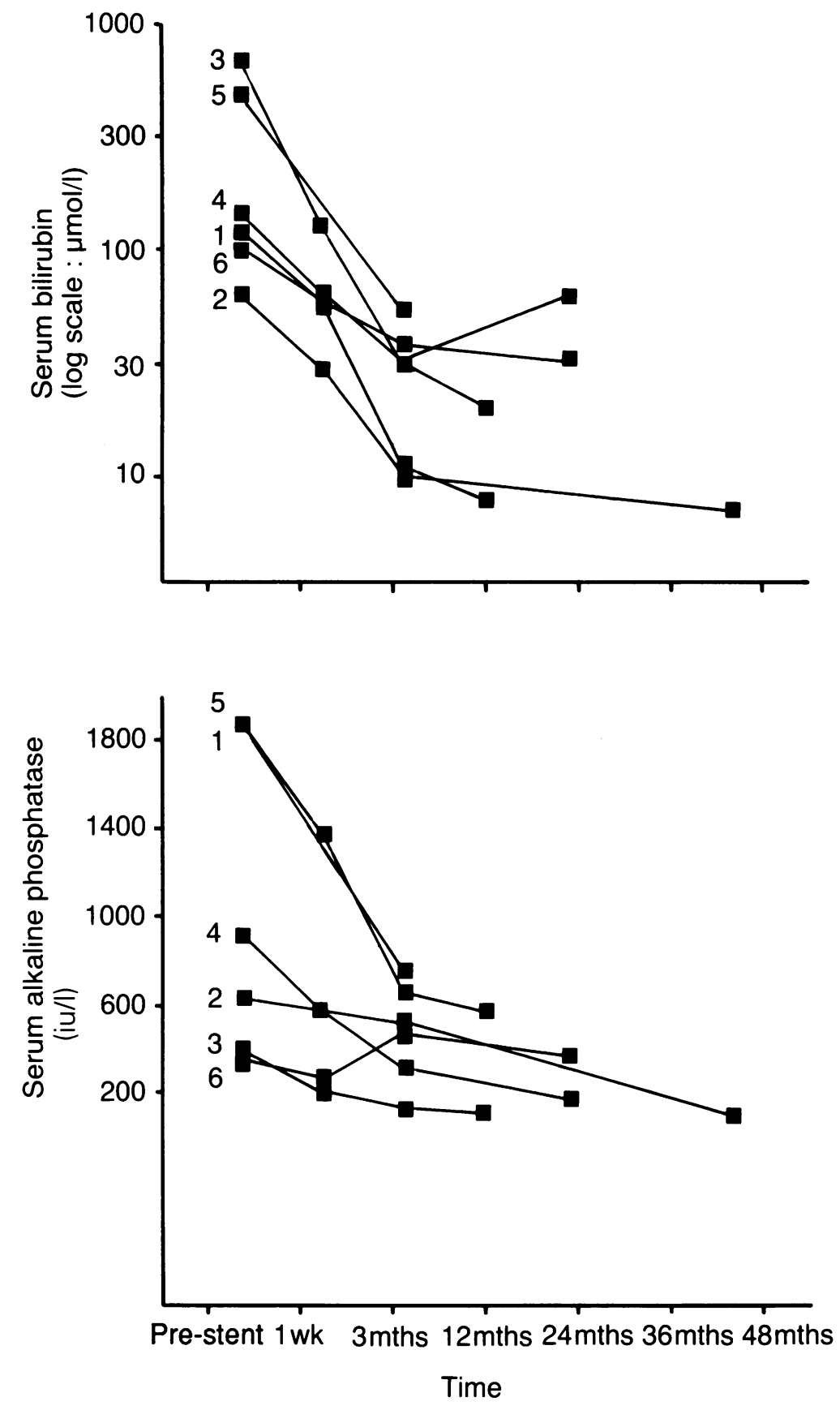

Figure 1: Bilirubin and alkaline phosphatase values immediately before stenting and serial measurements afterwards. The most dramatic changes were seen within the first week. Each patient is identified by a number as in the Table.

before and eight hours afterwards. Patients were sedated with intravenous diazemuls and pethidine, with the addition of hyoscine $n$-buytl hydrochloride to reduce gut motility. Diagnostic ERCs were carried out with a Pentax duodenoscope (SD32H). Cannulation of the common bile duct was successful at first attempt in all cases. All six patients had both intrahepatic and extrahepatic radiological features of primary sclerosing cholangitis. In five there were long strictures $(>1 \mathrm{~cm})$ in the common bile duct, and in two strictures affected the common hepatic and main hepatic ducts in addition to the common bile duct. Five patients also had moderately severe intrahepatic disease. Dominant strictures were initially dilated endoscopically using serial angioplasty inflation balloons up to a maximum of $8 \mathrm{~mm}$ (Surgimed, Meadox) through an Olympus TJF10 duodenoscope. Endoprostheses (straight, 10 FG, tailored length, Wilson-Cook) were positioned across strictures using standard guide wire techniques.

\section{Results}

Endoprostheses were placed endoscopically in five of the patients without resort to sphincterotomy or a combined percutaneous approach. In one patient a sphincterotomy was necessary to facilitate passage of the endoprosthesis. Satisfactory drainage was achieved at first insertion in five patients but the sixth required repositioning of the stent five days after the first attempt. Pruritus was completely relieved within seven days in five patients. Serum bilirubin and alkaline phosphatase values fell rapidly from mean (range) values of $266 \mu \mathrm{mol} / \mathrm{l}(63-681)$ and 1004 $\mathrm{iu} / \mathrm{l}$ (363-1965) respectively before stenting to 68 $\mu \mathrm{mol} / \mathrm{l}(30-128)$ and $600 \mathrm{iu} / \mathrm{l}(208-1367)$ after one week, and in three patients normal values were attained (Fig 1). One patient underwent transplantation five months after treatment because of clinical hepatic decompensation. The other five remain well and asymptomatic after a mean (range) of 25 months (12-49) follow up, apart from a variceal haemorrhage in one patient. Follow up ERCs in these five patients show measurable radiological improvement in four (Fig 2). The minimum calibre of extrahepatic ducts in these patients has at least doubled (Fig 3 ) and the length of the dominant extrahepatic stricture has been reduced appreciably in three.

Endoprostheses were removed without replacement in four patients six to 13 months after initial insertion, with sustained clinical improvement. In one other patient a stent removed at four months had to be replaced 10 months later because of a rising bilirubin concentration: there was a second prompt response in the bilirubin concentration after replacement.

Despite the use of prophylactic broad spectrum antibiotics, two patients developed bacteraemia after insertion of endoprosthesis but this resolved on continued treatment. Distension of the gall bladder developed in two patients during the first week after endoprosthesis insertion and required percutaneous drainage in one and cholecystectomy in the other. There were no complications related to follow up ERC or stent replacement.

\section{Discussion}

It is likely that in primary sclerosing cholangitis considerable secondary liver damage occurs as a result of bile acid stasis and recurrent bacterial infection that lead to destructive cholangitis and secondary biliary cirrhosis. Methods of improving biliary drainage in this condition are aimed at ameliorating the effects of these pathological mechanisms. According to one survival model for this condition, ${ }^{19}$ five of our patients had a 12 month survival probability of less than $50 \%$ at the time of referral and warranted consideration for transplantation. Five improved considerably after insertion of the endoprosthesis and remain well 12-49 months later.

Several reports attest to the desirability of improving biliary drainage in primary sclerosing 

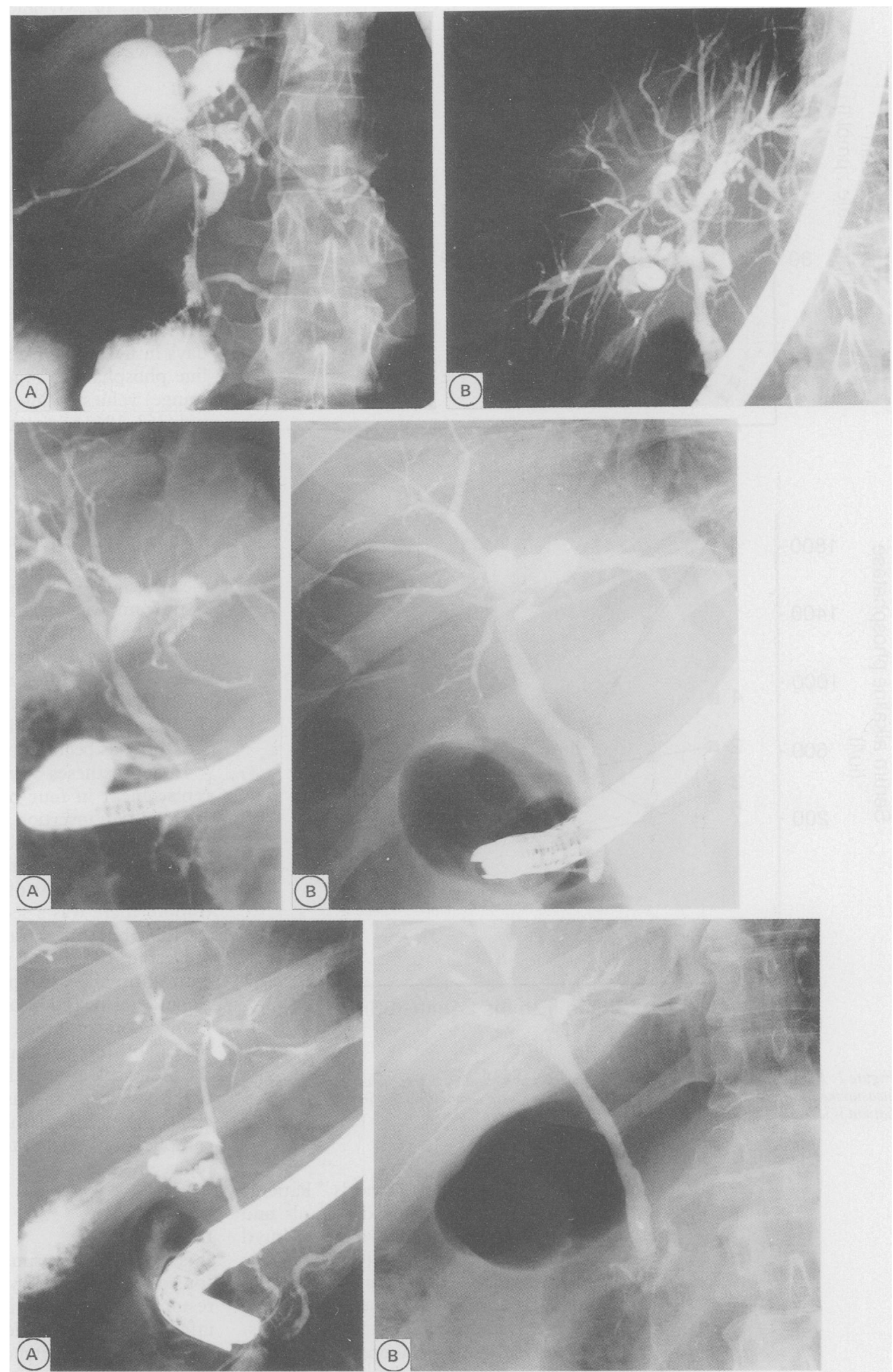

Figure 2: Radiological appearances before $(A)$ and after $(B)$ stenting in patients 1,2 , and 3 . The radiograms taken after stenting $(B)$ are from the review endoscopic retrograde cholangiograms taken at least three months after removal of stents.

cholangitis in an attempt to change the natural history of the disorder. Choledochotomy with $t$ tube insertion and percutaneous drainage was superseded by a more aggressive surgical approach with the establishment of a choledochoenteric anastomosis with or without endoprosthesis. ${ }^{2021}$ Cameron et $a l^{1322}$ extended this approach to include long term bilateral transhepatic Silastic catheters after excision of the hepatic duct bifurcation and bilateral hepaticojejunostomy. The catheters were irrigated antegradely on a daily basis and by this means 26 of 31 patients showed sustained improvement after a three and a half year period. Russel et $a l^{23}$ 


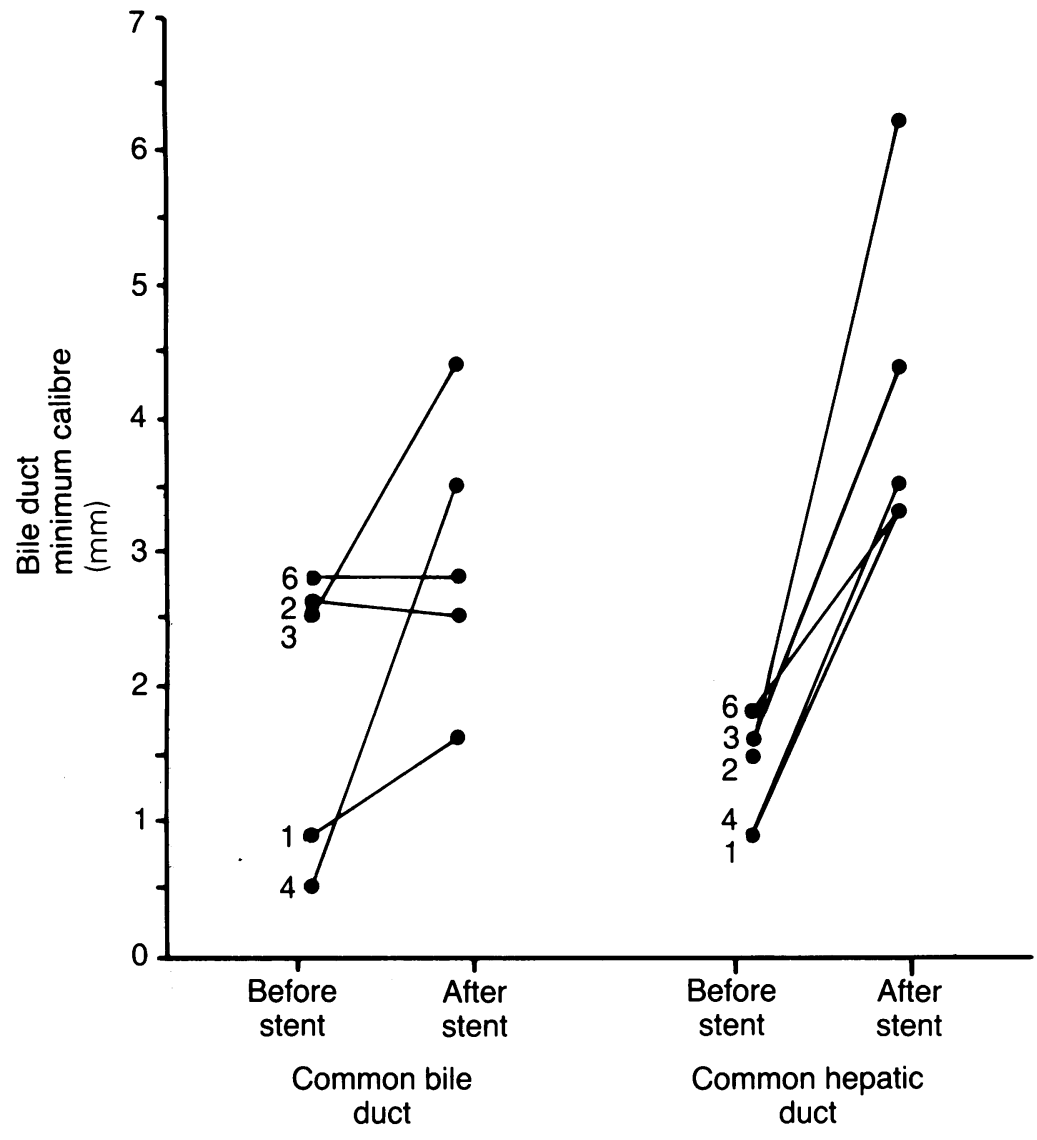

Figure 3: Radiological changes in extrahepatic bile duct calibre minima before and after stenting. Measurements were taken at review endoscopic retrograde cholangiography, which in four patients was at least three months after removal of stents. Each patient is identified by number as in the Table. No follow up measurements were available on the transplanted patient (No 5). scopic balloon dilatation for strictures in two patients with primary sclerosing cholangitis, and Johnson $e t a l^{28}$ performed sphincterotomy in 10, subsequently dilating eight and stenting three. In Johnson's series, patients' liver biochemistry improved and the number of admissions to hospital for cholangitis was reduced over a two year follow up period, but one patient developed peritonitis as a result of sphincterotomy. We chose to avoid a sphincterotomy whenever feasable because of the long term risks of bacterial colonisation. ${ }^{29}$ Three of our patients $(50 \%)$ had septic complications, in two attributable to distension of the gall bladder at cholangiography with subsequent obstruction to emptying by the endoprosthesis. This is a complication that can be difficult to avoid in primary sclerosing cholangitis because of the extensive strictures and the relatively high filling pressures required to obtain a cholangiogram.

To date, there is insufficient experience to determine how long stents should be left in place. Some advocate leaving a percutaneous endoprosthesis in place for 12-16 months ${ }^{1321}$ but others have reported such poor tolerance that the mean duration was $<6$ months. ${ }^{16}$ Huibregtse ${ }^{26}$ removed the endoprosthesis permanently in eight of 16 patients without detectable deterioration at follow up. In four of our patients the endoprostheses have been removed and the patients remain well with continued improvement in the radiological assessment of disease. In one other patient the stricture recurred after removal of the endoprosthesis at four months. This patient's clinical condition deteriorated subsequently but the deterioration was reversed with further endoprosthesis insertion. That dramatic radiological improvement can be achieved even with short term stenting (see Fig 2), confirms a previous report of long term clinical outcome after short term stenting in patients with primary sclerosing cholangitis. ${ }^{30}$ Similar beneficial effects have been reported in some series in which balloon dilatation was used alone. ${ }^{14-1628}$ In none of these series were the patients as severely ill as in the present one, and in our experience balloon dilatation alone does not lead to long lasting remission in jaundiced patients with primary sclerosing cholangitis. Frequent follow up with a view to restenting is important as strictures recur in up to $50 \%$ of patients. $^{14}$ 15 An advantage of the endoscopic method is that lesions can easily be redilated or restented if necessary without the risks attendant on repeated surgery or transhepatic puncture.

The possible effect of endoprosthesis drainage upon disease progression is of some interest. The radiological extent of extrahepatic disease is associated with a poorer prognosis in primary sclerosing cholangitis. ${ }^{31}$ Reducing bilirubin and cholestasis, and perhaps prevention of cirrhosis, should change the natural history of the condition in individual patients according to the clinical models currently being proposed. ${ }^{32} 33$ Thus, according to the Mayo Clinic prognostic model, stenting improved the risk categories of our patients from high to moderate risk (two patients) and moderate to low risk (four patients). Nonetheless, it seems likely that methods used to improve biliary-enteric drain- 
age are ultimately palliative in this condition and that most patients with primary sclerosing cholangitis will eventually require liver transplantation. With this in mind, endoscopic placement of endoprosthesis seems to be the drainage procedure of choice as it may avoid the disadvantages of surgical or percutaneous methods. A coordinated multicentre prospective study is required to assess the best means of biliary intervention in these patients and to determine whether broader criteria for such intervention are justified.

1 Chapman RWG, Arbough BAM, Rhodes J, et al. Primary sclerosing cholangitis: a review of its clinical features, cholangiography and hepatic histology. Gut 1980; $21: 870-7$.

2 La Russo NF, Wiesner RH, Ludwig, J, MacCarty RL. Primary sclerosing cholangitis. New Engl f Med 1984; 310 899-903.

3 Tinckler JS. Primary sclerosing cholangitis. Postgrad Med $\mathcal{F}$ 1971; 47: 666-70.

4 Burgert SL, Brown BP, Kirkpatrick RB, LeBrecque DR. Positive corticosteroid response in early primary sclerosing cholangitis [Abstract]. Gastroenterology 1984; 86: 1037.

5 Leiser A, Kadish U. Case report: beneficial effect of colchicine in a case of sclerosing cholangitis. Am $\mathcal{F}$ Med Sci 1986; 291: in a case $416-8$.

6 La Russo NF, Weisner RH, Ludwig J, MacCarty RL, Beever SJ, Zinsmeister AR. Prospective trial of penicillamine in primary sclerosing cholangitis. Gastroenterology 1988; 95: $1036-42$.

7 Lindor KD, La Russo NF, Wiesner RH. Prednisone and colchicine are not of benefit after two years in patients with primary sclerosing cholangitis [Abstract]. Hepatology 1989 10: 638

8 Kaplan MM, Arora S, Pincus SH. Primary sclerosing cholangitis and low-dose oral pulse methotrexate therapy. Ann Intern Med 1987; 106: 231-5.

9 Stiehl A, Raedsch G, Thielmann L. Treatment of primary sclerosing cholangitis with ursodeoxycholic acid: first result of a controlled study [Abstract]. Hepatology 1989; 10: 612 .

10 Grijm R, Huibregtse K, Bartelsman J, Mathus Vliegen EMH, Dekker W, Tytgat GN. Therapeutic investigations in primary sclerosing cholangitis. Dig Dis Sci 1986; 31: 792-8.

11 Allison MC, Burroughs AK, Nune P, Summerfield JA. Biliary lavage with corticosteroids in primary sclerosing cholangitis a clinical, cholangiographic and bacteriologic study. f Hepatol 1986; 3: 118-22.

12 Thompson JS, Wood RP, Burnett DA, Shaw BW, Rikkers LF The role of non-transplant procedures for sclerosing

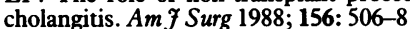

13 Cameron JL, Pitt HA, Zinner MJ, et al. Resection of hepatic duct bifurcation and transhepaticstenting for sclerosing duct bifurcation and transhepaticstent

14 Mueller PR, vanSonnenberg E, Ferruci JT, et al. Biliary stricture dilatation: multicentre review of clinical management in 73 patients. Radiology 1986; 160: 17-22

15 May GR, Bender CE, LaRusso NF, Wiesner RH. Nonoperative dilatation of dominant strictures in primary sclerosing cholangitis. Am $\mathcal{F}$ Radiol 1985; 145: 1061-4.

16 Skolkin MD, Alspaugh JP, Casarella WJ, Chuang VP Galambos JT. Sclerosing cholangitis: palliation with percutaneous cholangioplasty. Radiology 1989; 170: 199-206.

17 Marsh JW, Iwatsuki S, Makowka L, et al. Orthotopic live transplantation for primary sclerosing chonangitis. Ann Surg 1988; 207: 21-5.

18 Roberts MS, Pinson CW, Karlson C, et al. Predictors of intraoperative death and long-term survival in liver transplantation: a multistage analysis. Transplant Proc 1989; 21 2439-42.

19 Lebovics E, Palmer M, Woo J, Schaffner FS. Outcome of primary sclerosing cholangitis: analysis of long-term observation fo 38 patients. Arch Intern Med 1987; 147: 729-31.

20 Pitt HA, Thompson HH, Tompkins RK, Longmire WP. Primary sclerosing cholangitis: results of an aggressive surgical approach. Ann Surg 1982; 196: 259-68.

21 Wood RAB, Cuschieri A. Is sclerosing cholangitis complicating ulcerative colitis a reversible condition. Lancet 1980; ii: ing ulc.

22 Cameron JL, Gayler BW, Herlong HF, Maddrey WC. Sclerosing cholangitis: biliary reconstruction with Silastic transhepatic stents. Surgery 1983; 94: 324-30.

23 Russel E, Yrizarry JM, Huber JS, et al. Percutaneous transjejunal biliary dilatation: alternative management for benign strictures. Radiology 1986; 159: 209-14.

24 Krige JEJ, Terblanche J, Harries-Jones EP, Bornman PC Primary sclerosing cholangitis: biliary drainage and dilatation. Brf Surg 1987; 74: 54-7.

25 Huibregtse K, Tytgat GN. Palliative treatment of obstructive jaundice by transpapillary introduction of large bore bile duct endoprosthesis. Gut 1982; 23: 371-5.

26 Huibregtse $K$. Therapeutic investigations in primary sclerosing cholangitis. In: Endoscopic biliary and pancreatic drainage. Stuttgart: George Thieme Verlag, 1988: 78-85.

27 Siegal JH, Guelrud M. Endoscopic cholangiopancreatography: hydrostatic balloon dilatation in the bile duct and pancreas. Gastrointest Endosc 1983; 29: 99-103.

28 Johnson GK, Geenan JE, Venu RP, Hogan WJ. Endoscopic treamtent of biliary duct strictures in sclerosing cholangitis: follow-up assessment of a new therapeutic approach. Gastrointest Endosc 1987; 33: 9-12.

29 Escourrou J, Cordova JA, Lazorthes F, Frexinos J, Ribet A. Early and late complications after endoscopic sphincteroEarly and late complications after endoscopic sphincterotomy for biliary lithiasis with and

30 Hamilton I, Soutar JS, Bouchier IA, Cuschieri A. Short-term biliary dilatation and stenting in primary sclerosing holangitis. $\mathcal{F}$ Clin Gastroenterol 1987; 9: 70-5.

31 Sherlock S. Primary sclerosing cholangitis. In: Diseases of the liver and biliary system. 8th ed. Oxford: Blackwell Scientific 1988: 289-300.

32 Helzberg JH, Petersen JM, Boyer JL. Improved survival with primary sclerosing cholangitis: a review of clinicopathologic features and comparison of symptomatic and asymptomatic patients. Gastroenterology 1987; 92: 1869-75.

33 Wiesner RH Grambsch PM, Dickson DR et al. Primary sclerosing cholangitis: natural history, prognostic features and survival analysis. Hepatology 1989; 10: 430-6. 